\title{
EDITORIAL
}

\section{Special Issue on the Great East Japan Earthquake and the Activities of Members and Alumni of the School of Medicine, Keio University}

\author{
Seitaro Fujishima ${ }^{1}$ and Makoto Suematsu ${ }^{2}$ \\ ${ }^{1}$ Editor-in-Chief, The Keio Journal of Medicine \\ ${ }^{2}$ Dean, The School of Medicine, Keio University, Tokyo, Japan
}

\begin{abstract}
About the Earthquake
The magnitude-9.0 Great East Japan Earthquake, which struck at 14:46 JST on March 11, 2011, was the largest ever recorded in Japan. Strong quakes were felt not only in Tohoku, the closest region to the epicenter, but also nationwide from Hokkaido to Kyushu. This exceptional event was followed by huge tsunami waves that severely damaged the Fukushima Daiichi nuclear power plant, which consequently developed into an unprecedented crisis. A huge amount of infrastructure and innumerable buildings were damaged in more than 17 prefectures, over 19,000 people died or went missing in 12 prefectures, and more than 5000 people were injured in 20 prefectures. $^{1}$ Successive failures or shutdowns of nuclear and non-nuclear power plants brought a sustained shortage of electricity across a wide area of Japan, a situation that seriously affected our university and hospital as well as our daily lives and living environment.

In response to the crisis, in addition to national and local governmental initiatives, numerous voluntary organizations, companies, schools, and individuals from all over Japan and worldwide headed toward the disaster-stricken area to help rescue victims, deliver subsistence goods, remove rubble, and restore infrastructure. Thanks to the strenuous activities of the Japan Self-Defense Forces, United States (U.S.) Forces, and devoted civilians, major items of infrastructure, including highways, shinkansen (bullet train) tracks, airports, and harbors were restored quite quickly. The damaged nuclear plants were finally stabilized with the best possible efforts, although it will likely be more than three decades before they are finally decommissioned. ${ }^{2}$
\end{abstract}

\section{Medical Care in Tohoku}

After the Great Hanshin and Awaji Earthquake of 1995, the Japanese Ministry of Health, Labor, and Welfare (MHLW) established disaster medical assistance teams (DMATs) that can deploy to a stricken area mostly within 48 hours, following a similar system to that used in the U.S. In comparison with U.S. DMATs, Japanese DMATs are smaller in size and are composed of one or two doctors, nurses, and a logistical staff member, so as to be able to travel by car. ${ }^{3}$ In the current crisis, a total of 340 teams from all over Japan were dispatched to Miyagi, Iwate, Fukushima, and Ibaraki prefectures during the initial 12 days. ${ }^{4}$ In contrast to the 1995 earthquake, in which asphyxia and being crushed were the biggest dangers, more than $90 \%$ of the victims of the Great East Japan Earthquake died from drowning, and consequently DMATs played a major role not in rescue, but in patient transport, hospital support, and medical care, in cooperation with local medical professionals. In addition, a number of governmental and voluntary medical teams from all over Japan and worldwide were deployed soon after the disaster.

Since most of the stricken area was originally underpopulated with medical professionals and because full recovery of medical resources and public transport will take a long time, support for regular medical care has been persistently necessary, even though the acute phase of the disaster has come to an end. Furthermore, the sustained release of radiation from the devastated nuclear power plant resulted in a significant exodus of residents, including medical professionals, from Fukushima, which has hampered the recovery of medical networks in this area.

\section{Medical Rescue Teams from Keio University}

Soon after the disaster, Keio University, including faculties of Keio University School of Medicine, started planning to send medial rescue teams to the stricken area. However, as was the case with previous disasters, it was hard to access accurate information about what was going on and what we could do. In response to the call for volunteers, many faculty members and fellows applied 
to join the teams. The initial teams were organized to include a physician, a surgeon, a nurse, and a radiation specialist; they departed for Kesennuma city, located at the northern edge of Miyagi prefecture, 6 days after the earthquake, to collect accurate information and also to give medical care. One of the authors (SF) also joined the team as a team leader. During our stay, to find sick patients who needed to be admitted to a hospital and to give primary medical care, we visited a small island and an isolated district. At one point, we arranged for a sick patient to be transported to hospital by helicopter. We also prescribed medicines for various chronic diseases, such as hypertension, dyslipidemia, diabetes mellitus, bronchial asthma, and thrombotic diseases, among others, in addition to medicine for acute infectious diseases and mild psychiatric symptoms such as insomnia. Since the level of daily medical care in this rural area was as high as that in urban areas, patients were relieved to be able to receive their regularly prescribed medicines from supplies that we took with us from Tokyo. On another day, we examined more than 100 patients and prescribed similar medicines at a temporary clinic set up in a sports center that was housing more than 1000 refugees. Following us, teams two and three went to Kesennuma, teams four to six to Rikuzentakada in Iwate, and teams seven to nine to Soma in Fukushima. Team members and the areas covered were flexibly changed to maximally fit the local needs at each time point.

In addition to the dispatch of medical rescue teams, of our school of medicine numerous members and almuni were actively involved in organizing or giving various types of medical care. As we mentioned above, Keio University School of Medicine and Keio University Hospital, located in the center of Tokyo, were significantly damaged and disrupted by the earthquake. Under the leadership of the School Dean and Hospital Director, we could overcome such problems very quickly and systematically.

In this special issue of the Keio Journal of Medicine, which is published just 1 year after this unparalleled crisis, representative activities by the faculties, members, and alumni of the School of Medicine, Keio University, are presented. Concretely, the collaborative efforts between Tohoku University and Keio University to help alleviate the disastrous situation are reported by Prof. Okano, the innovative mobile ophthalmologic clinic project "the Vision Van" is described by Dr. Oshima, the activities of the regional medical association and pediatric care in $\mathrm{Fu}-$ kushima are depicted by Dr. Kikuchi, subacute mental care activities in Fukushima are reported by Dr. Kato, and how to manage the issues associated with radiation damage is described by Prof. Shigematsu. We hope that these featured articles will be of some assistance to those who are involved in disaster planning or who may need to provide medical assistance during a future disaster.

\section{Acknowledgments}

On behalf of Keio University School of Medicine, Keio Medical Society, and Keio Journal of Medicine, we greatly thank Mr. Koki Ando and Mr. Noritaka Ando, CEO and CMO, respectively, Nissin Foods Holdings Co., Ltd.; Nobutada Saji, Chairman of the Board, Suntory Holdings Limited; and Professor Heizo Takenaka for their immediate and generous actions in supporting the logistics of our rescue teams. We also thank Reijiro Hattori and numerous Keio and KP alumni for their ongoing support for victims of the earthquake.

\section{REFERENCES}

1. Latest summary of the damage caused by the Great East Japan Earthquake and associated police action (in Japanese). In: National Police Agency Emergency Disaster Headquarters Press Release. Tokyo: National Police Agency; December 15, 2011. Available from: http://www.npa.go.jp/archive/keibi/biki/higaijokyo.pdf

2. Status of Fukushima Daiichi and Fukushima Daini Nuclear Power Stations after the Great East Japan Earthquake. [cited December 17, 2011]; Available from: http://www.tepco.co.jp/en/nu/ fukushima-np/index-e.html.

3. Fuse A, Yokota H: An analysis of Japan Disaster Medical Assistance Team (J-DMAT) deployments in comparison with those of J-DMAT's counterpart in the United States (US-DMAT). J Nihon Med Sch 2010; 77: 318-324. [Medline] [CrossRef]

4. Koido Y: DMAT activities in the Great East Japan Earthquake and problems to be solved (in Japanese). In: DMAT Secretariat Ministry of Health, Labor, and Welfare, Tokyo 2011; Available from: http://www.mhlw.go.jp/stf/shingi/2r9852000001khc1att/2r9852000001khkf.pdf. 